\title{
Analysing Insurer Rating Transitions with Different Economic and Industry Cycles
}

\author{
Yuling Wang \\ School of Finance, Shanghai University of Finance and Economics, Guoding Road 777, Shanghai 200433, \\ China. \\ E-mail: wang.yuling@mail.shufe.edu.cn
}

Changes in insurer ratings reflect changes in their financial strength. For the first time, unconditional and conditional matrices for U.S. property-liability insurer ratings during the period 1995-2006 are estimated and compared across different economic and industry cycles. Findings indicate that the distribution of insurer rating changes varies across different economic and industry cycles and insurers usually perform better when economic and industry conditions are favourable. Regression analyses generally confirm this relationship. Our results give a new perspective for regulators, consumers and investors to measure and manage insurer financial risks across time.

The Geneva Papers (2010) 35, 435-451. doi:10.1057/gpp.2010.15

Keywords: property-liability insurer; insurer rating matrices; economic cycles; industry cycles

\section{Introduction}

Transition matrices are at the centre of modern bond credit management when scholars link bond price changes directly to their credit changes. For example, J.P. Morgan offers an advanced risk management product called CreditMetrics ${ }^{\mathrm{TM}}$ to their customers. Analogous to the risk associated with corporate debt, credit risk also applies to insurance policies: Insurance policy-owners face counter-party risk in that the insurer may be financially unable to meet policy-holder obligations. Investors are concerned about the risks in the defaultable loan contracts, issued by insurers. In addition, reinsurers may be financially unable to make good on their contractual obligations to their ceding companies. Unlike other financial institutions, insurers' main liabilities are the promised claim payments, which may stretch over several years. So for customers it is difficult and expensive to jump ship overnight like the bondholders or depositors. Insolvency monitoring is crucial to protect customers. The failure of a large insurance company may even contribute to the deterioration of the entire financial system. The 2008 federal bailout of AIG indicates that the federal government is concerned about the broader economic implications of the failure of a large insurance company. In this sense, credit rating agencies play an important role in monitoring financial institution's solvency. Regulators have used the credit ratings as well, or permitted ratings to be used for monitoring purposes. For example, banking regulators can allow banks to include borrowers' credit ratings in assessments of the adequacy of banks' capital reserve, under the Basel II agreement of the Basel Committee on Banking Supervision. On the other hand, insurance companies seek 
ratings to reduce ex ante uncertainty about insolvency risk. ${ }^{1}$ Insurance companies may also react to rating information by adjusting their capitalisation levels. Cummins and $\mathrm{Nini}^{2}$ explored the trends of dramatic growth in equity capitalisation in the propertyliability insurance industry between 1970 and 1999, and concluded that "some insurers may have accumulated additional capital to protect their financial ratings" and therefore rating agencies were becoming more important. Rating information can influence consumers' purchase decisions. Sommer ${ }^{3}$ found that the price of insurance was negatively related to insurer default risk. ${ }^{4}$ Although state guaranty funds provided substantial protection to policyholders, Epermanis and Harrington ${ }^{5}$ found that premiums declined significantly after ratings fell.

A.M. Best Company has been measuring insurers' risk for over 100 years. Their ratings consider both quantitative and qualitative factors which A.M. Best believes impact an insurer's financial strength. General bond rating probabilities are inappropriate for assessing insurance credit risks because their operations are unique. There is evidence that the distributions of rating transitions vary across industries. ${ }^{6}$

Academics and practitioners have found that bond rating migrations vary across different economic cycles. For example, Carty $^{7}$ examined Moody's bond ratings from 1920 to 1996 and indicated that the credit qualities of different issuers were correlated with various macroeconomic, industrial, geographic and temporal factors. Nickell et al. ${ }^{8}$ and Bangia et $a l^{9}$ both documented that bond rating transitions differed over different business cycles. In particular, Nickell et al. ${ }^{8}$ examined the rating transition matrices across different industries on the stage of the business cycle. Other studies focused on exploring the impact of macroeconomic factors on default intensity, and all demonstrated a connection between the bond rating transitions and macroeconomic factors. ${ }^{10}$

Previous research has studied insurer rating determinants from the viewpoint of the rating agency. Prominent are Pottier and Sommer ${ }^{1}$ and Gaver and Pottier, ${ }^{11}$ and both studies focused on firm-specific factors. Prior studies also provide evidence that general economic factors were important predictors of insurer failures. For example, Browne and Hoyt ${ }^{12}$ found evidence that economic and market factors could be used in predicting the property-liability insurer insolvencies. Browne, Carson and Hoyt ${ }^{13}$ demonstrated a similar relationship in life-health insurer insolvencies. ${ }^{14}$

\footnotetext{
${ }^{1}$ Pottier and Sommer (1999).

${ }^{2}$ Cummins and Nini (2002).

${ }^{3}$ Sommer (1996).

${ }^{4}$ also see Phillips et al. (1998).

${ }^{5}$ Epermanis and Harrington (2006).

${ }^{6}$ (Nickell et al. (2000); Lando and Skødeberg (2002).

${ }^{7}$ Carty (1997).

${ }^{8}$ Nickell et al. (2000).

${ }^{9}$ Bangia et al. (2002).

${ }^{10}$ Kavvathas (2001); Duffie et al. (2007); Figlewski et al. (2008).

${ }^{11}$ Gaver and Pottier (2005).

12 Browne and Hoyt (1995).

13 Browne et al (1999).

${ }^{14}$ Insurer rating does not include a specific "default" category, but it reflects the likelihood of default. A.M. Best Company uses the term "impairment", a broader concept than default, to illustrate any official
} 
Table 1 Best's financial strength ratings

\begin{tabular}{ll}
\hline Secure & Vulnerable \\
\hline $\mathrm{A}++, \mathrm{A}+$ (Superior) & $\mathrm{B}, \mathrm{B}-$ (Fair) \\
$\mathrm{A}, \mathrm{A}-($ Excellent) & $\mathrm{C}++, \mathrm{C}+$ (Marginal) \\
$\mathrm{B}++, \mathrm{B}+($ Good) & $\mathrm{C}, \mathrm{C}-$ (Weak) \\
& $\mathrm{D}$ (Poor) \\
& $\mathrm{E}$ (Under Regulatory Supervision) \\
& F (In Liquidation) \\
& S (Rating Suspended) \\
\hline
\end{tabular}

Source: Best's Rating Center.

In this paper, we examine insurer rating migrations using Best's property-liability insurer ratings for the period 1995-2006. Insurer rating matrices are constructed and compared under different economic and industry conditions. The remainder of this paper is organised as follows: The next section describes the data and methodology used to construct the insurer rating matrices; the subsequent section presents the matrices in different economic and industry conditions; the penultimate section presents the regression results and the last section presents the conclusion and summarising remarks.

\section{Data and methodology}

\section{Property-liability insurer ratings}

The Best's Financial Strength Ratings (FSR) used in this study are published by A.M. Best Company. FSR “... provide an opinion of an insurer's financial strength and ability to meet ongoing obligations to policy-holders". ${ }^{15}$ The earliest ratings go as far back as 1995, but most of the ratings start in mid-1996. The first rating change happens in January 1997. The last rating is in December 2006. Rating renews cluster in June. Table 1 lists the rating classes and their brief descriptions. $\mathrm{A}++, \mathrm{A}+, \mathrm{A}, \mathrm{A}-$, $\mathrm{B}++$, and $\mathrm{B}+$ are considered "secure grade" and $\mathrm{B}, \mathrm{B}-, \mathrm{C}++, \mathrm{C}+, \mathrm{C}, \mathrm{C}-, \mathrm{D}, \mathrm{E}$, and $\mathrm{F}^{16}$ are "vulnerable grade". One non-letter rating is also included in this study: Not Rated (NR). ${ }^{17} \mathrm{NR}$ is assigned to the companies whom A. M. Best Company issues financial reports. NR is assigned for the following reasons: (1) insufficient data;

action taken by an insurance department to restrict the insurance business activity of an insurer. The details can be found in A.M. Best Company (2008a, b).

${ }^{15}$ See www.ambest.com/ratings/guide.asp.

${ }^{16}$ Except those insurers that have been placed under an order of liquidation by a court of law, $\mathrm{F}$ is also assigned to those insurers that voluntarily agree o liquidate or dissolve their charters when they are generally not insolvent.

${ }^{17}$ This category is analogous to withdrawn rating category (WR) in the Moody's and not-rated category (NR) in the S\&P. Carty (1997) argued that migrations to this category were mainly associated with exit from the debt markets and only about 13 per cent of the migrations were related to increased default risk. While insurer ratings have no associated maturity dates. 
Table 2 P-L insurer rating distribution of first and last rating, 1995-2006

\begin{tabular}{|c|c|c|c|c|}
\hline & \multicolumn{2}{|c|}{ First rating } & \multicolumn{2}{|c|}{ Last rating } \\
\hline & Number & Percentage & Number & Percentage \\
\hline $\mathrm{A}++$ & 175 & 4.50 & 84 & 2.16 \\
\hline $\mathrm{A}+$ & 431 & 11.08 & 430 & 11.05 \\
\hline A & 763 & 19.61 & 712 & 18.30 \\
\hline A- & 659 & 16.94 & 565 & 14.52 \\
\hline $\mathrm{B}++$ & 218 & 5.60 & 200 & 5.14 \\
\hline $\mathrm{B}+$ & 166 & 4.27 & 111 & 2.85 \\
\hline Total secure grade & 2,412 & 62.01 & 2,102 & 54.04 \\
\hline B & 89 & 2.29 & 51 & 1.31 \\
\hline B- & 40 & 1.03 & 29 & 0.75 \\
\hline $\mathrm{C}++$ & 13 & 0.33 & 14 & 0.36 \\
\hline $\mathrm{C}+$ & 12 & 0.31 & 3 & 0.08 \\
\hline $\mathrm{C}$ & 11 & 0.28 & 3 & 0.08 \\
\hline $\mathrm{C}-$ & 2 & 0.05 & 4 & 0.10 \\
\hline $\mathrm{D}$ & 9 & 0.23 & 0 & 0.00 \\
\hline E & 16 & 0.41 & 18 & 0.46 \\
\hline $\mathrm{F}$ & NA & NA & 15 & 0.39 \\
\hline $\mathrm{S}$ & NA & NA & NA & NA \\
\hline Total vulnerable grade & 192 & $4.94 \%$ & 137 & $3.52 \%$ \\
\hline NR & 1,286 & 33.06 & 1,651 & 42.44 \\
\hline Total & 3,890 & 100 & 3,890 & 100 \\
\hline
\end{tabular}

(2) insufficient size or operating experience; (3) inapplicable rating procedure; (4) company request; (5) not formally followed. Our sample includes 3,890 U.S. insurance entities $^{18}$ and 37,054 rating assignment observations.

Table 2 presents the rating distributions for the first and the last rating in our sample period. In our sample, over 60 per cent of insurers hold a secure grade in their initial period, only about 5 per cent hold a vulnerable grade, around 33 per cent are not rated. In the last rating, the secure grades drop to 54.04 per cent, vulnerable grades also drop to 3.52 per cent, and NR grades increase to 42.44 per cent. We find NR is a heavily weighted grade among insurance companies. Including NR in our analysis allows us to fully understand the overall insurer rating dynamics.

\footnotetext{
${ }^{18}$ Following the bond rating studies, insurance groups and their subsidiaries are counted separately as their ratings are not always rated the same (Carty and Lieberman, 1996). The subsidiaries, from their standalone ratings, can receive full rating uplift, partial rating uplift or no rating uplift of their parents. The details are explained in A.M. Best Company (2008a, b).
} 


\section{Methodology}

Insurer ratings are not renewed as frequently as bond ratings. During our sample period (1995-2006), some insurers are rated less than four times. Here we will apply a cohort method, commonly used by rating agencies, to estimate the probabilities of insurer rating migrations. This technique is widely accepted in bond rating transition estimations. The traditional cohort method is described as follows: Suppose there are $N_{i}$ issuers in the rating category $i$ at the beginning of the year and $N_{i j}$ issuers move to category $j$ within the year, then the transition rate of that year is calculated as

$$
\hat{P}_{i j}=\frac{N_{i j}}{N_{i}}, \quad i \neq j
$$

Although this method ignores the within-year transitions which may underestimate low-grade default intensities and overestimate high-grade ones, ${ }^{19}$ this technique gives a snapshot of the evolution of the rating movements at a specific point of time.

\section{Insurer rating matrices}

\section{Unconditional transition matrices}

Before estimating our conditional transition matrices, we estimated the unconditional transitions for both one year and 10 years. The first rating change occurred in January 1997 and last rating in December 2006, so we can observe 10-year rating migrations. Table 3 presents the one year unconditional transition matrix for our sample and Table 4 shows the 10-year unconditional transition matrix. Each row gives the initial rating and each column corresponds to the terminal rating during the course of the specific period. ${ }^{20}$

It is not very hard to observe that the lower rating categories are more volatile than higher rating categories in both Tables 3 and 4 . For example, in the one year rating matrix, there is an over 80 per cent probability that A-rated (including $\mathrm{A}++, \mathrm{A}+, \mathrm{A}$ and $\mathrm{A}-$ ) observations will keep their ratings. In contrast, 60-70 per cent of B-rated (including $\mathrm{B}++, \mathrm{B}+, \mathrm{B}$ and $\mathrm{B}-$ ) keep their ratings while around 40 per cent of $\mathrm{C}$-rated (including $\mathrm{C}++, \mathrm{C}+, \mathrm{C}$ and $\mathrm{C}-$ ) keep their ratings. $\mathrm{D}, \mathrm{E}$ and $\mathrm{F}$ vary within 20 to 50 per cent. For the 10 -year rating matrix, it is much more volatile. In the 10 -year rating matrix, A-rated group, NR ratings and $F$ staying in the same rating across the 10 years are largely proportional; ratings below $\mathrm{B}$ (except $\mathrm{F}$ ) maintaining the same rating are minimal. For example, no insurers who were rated $\mathrm{C}$ in the beginning of the 10 -year period were still rated $\mathrm{C}$ at the end of the 10 -year period. It is also noticeable that NRs maintain their ratings with probabilities of 97.5 per cent within a year and 71.8 per cent within 10 years, respectively, and low-rated insurers are more likely to

\footnotetext{
${ }^{19}$ Kavvathas (2001).

${ }^{20}$ It assumes that transition probability from rating $i$ to $j$ follows a constant parameter, $p_{i j}$, in a specific period.
} 


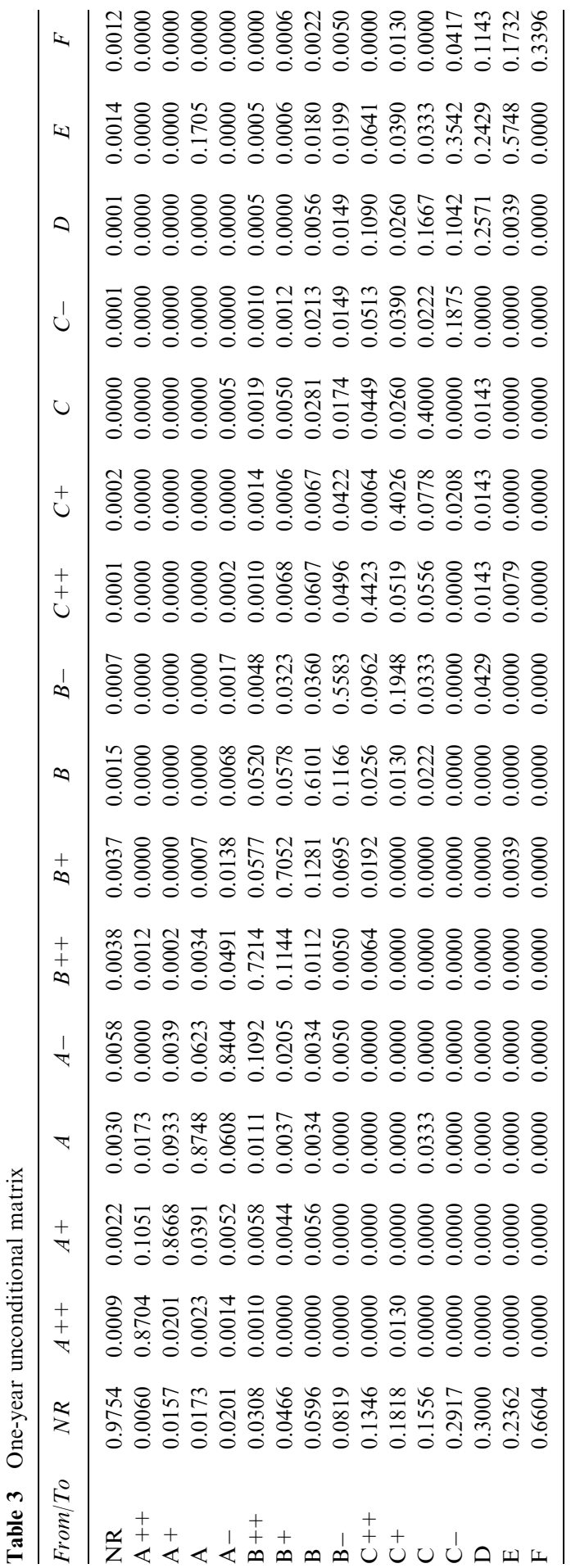




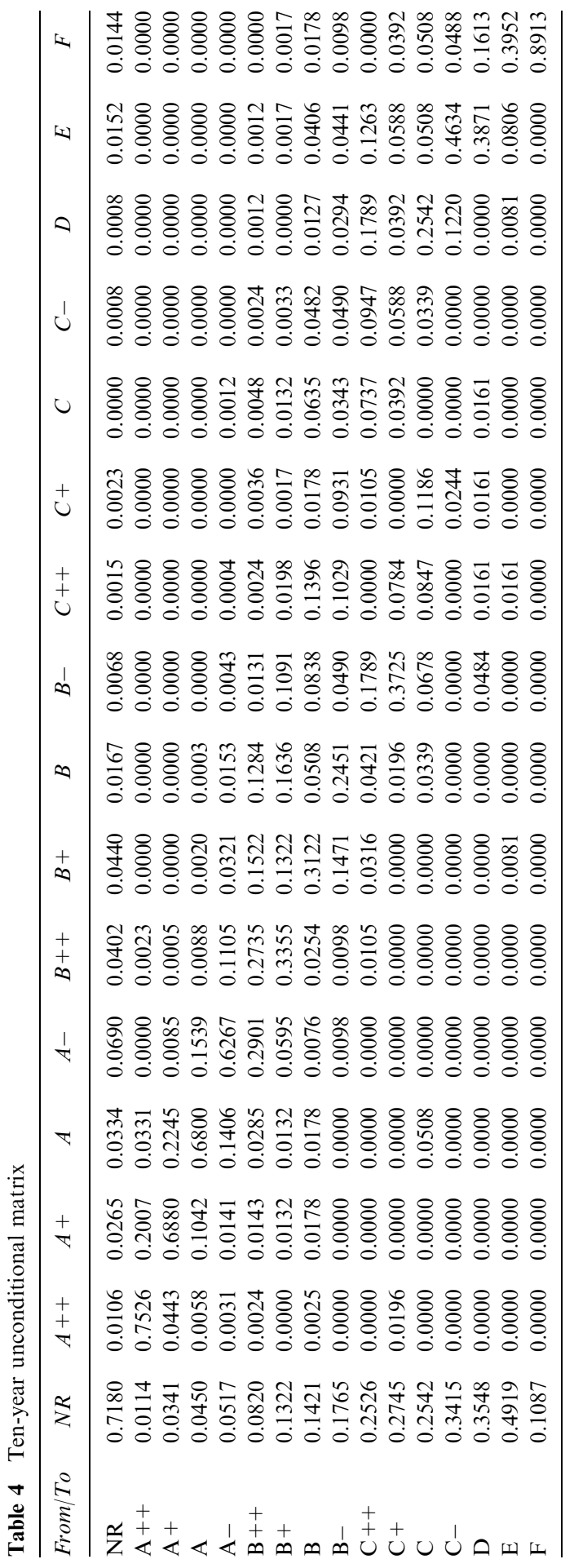




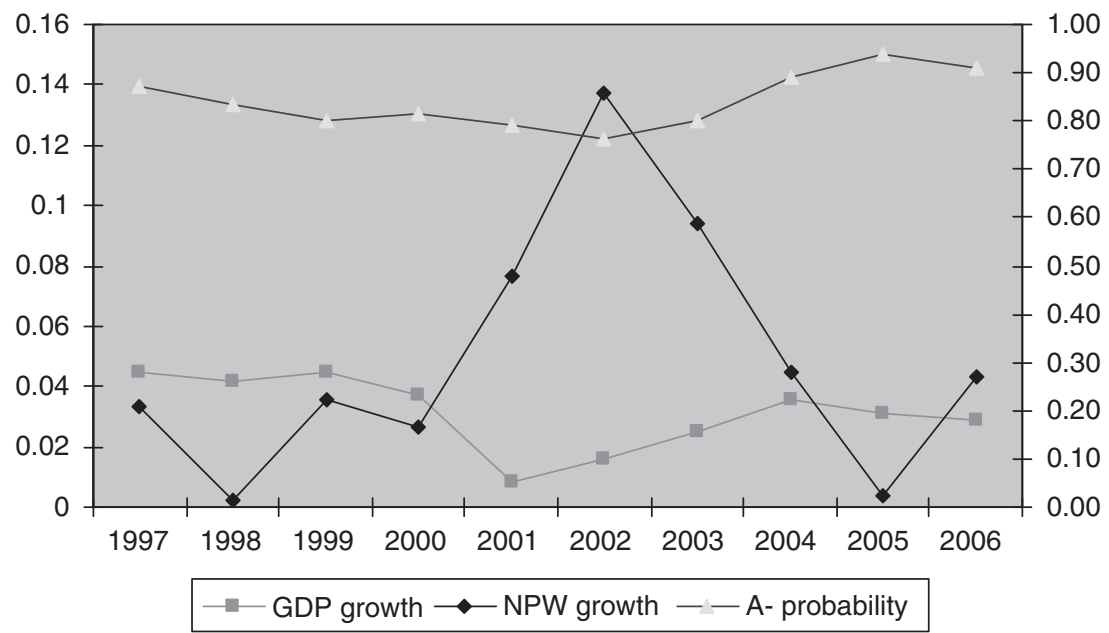

Figure 1. The probability for unchanged A- against GDP and NPW growth rate (1997-2006). Real U.S. GDP growth is collected from BEA website. NPW growth is collected from Insurance Fact Book. They are all annual series. A- probability represents the probability to stay in A- each year from 1997 to 2006.

change to "NR". It may indicate that the insurer who transits to "NR" have suffered a deterioration in financial strength from which they may not be able to recover.

To investigate the dependence of the rating on the conditions of the economy and industry, we model the relationships between the probabilities for non-changed $\mathrm{A}-{ }^{21}$ across 10 years $^{22}$ and the real U.S. Gross Domestic Product (GDP) growth rate and Net Premium Written (NPW) growth rate in Figure 1. The GDP growth rate and NPW growth rate are used to approximate the different levels of economic and industry activities, respectively. In Figure 1, we can observe that the probability of unchanged A- roughly follows the same trend as GDP growth, but is opposite to NPW growth. Especially in 2002, NPW growth peaked and GDP growth was very low (2001 was the lowest), and the probability that an A - insurer could maintain its rating is the lowest. The correlation between "A- probability" and NPW growth is -0.65 ; the correlation between "A- probability" and GDP growth is 0.37 . Compared to the trends of GDP growth and NPW growth, the probability of an A- rated insurer of changing is very stable.

\section{Conditional matrices on economic cycles}

Rating transitions may vary under different economic conditions. Bangia et al. ${ }^{9}$ incorporated systemic factors in modelling bond credit changes over time. Although asset value changes can be used to compare to the critical distances of rating

\footnotetext{
${ }^{21} \mathrm{~A}-$ is considered as an important rating for an insurer to hold to attract business. See note 5.

${ }^{22}$ Here we estimate one year rating matrices for 1997-2006 respectively, so we can get the probability for unchanged $\mathrm{A}$ - for each year.
} 
transitions for each asset, "... the ratings transitions (of which default is a specific case) are correlated due to the correlation in asset values between firms through the systematic risk factor". ${ }^{9}$ Similar to Nickell et al., ${ }^{8}$ we separate our set of sample years into three economic periods: Peak, Normal, and Trough based on the real U.S. GDP level by terciles in our sample period. The highest real GDP growth is 4.5 per cent, and the lowest is 0.8 per cent. So the range for the Peak is 3.5-4.5 per cent; for the Normal is $1.8-3.53$ per cent; for the Trough is $0.8-1.8$ per cent. Results are presented in Table 5.

To compare the matrices based on economic cycles using the one year unconditional matrix shown in Table 3, we first calculate the standard errors for the rating transition probabilities in Table 3. Rating transition can be considered as a binomial variable: It starts with rating $i$, and can either move to $j$ or to $k=1, \ldots, N$, where $k \neq j$. Then the standard error for $\hat{P}_{i j}$ can be calculated as $\sqrt{\hat{P}_{i j}\left(1-\hat{P}_{i j}\right) / n}$, where $n$ is the frequency of moving to rating $j$ starting from rating $i$. Then $t$-statistics can be calculated as the difference between the rating probabilities in different economic periods and the cooperated rating probabilities in the one year unconditional rating matrix divided by the standard errors of the conditional matrices. Here we suppose that one year unconditional probabilities are constant. We record in bold type of those that are significant at the 0.05 level. Table 5 shows that most of the significant observations cluster in the "Secure" ratings, although this may be partly caused by the small number of insurers in the "Vulnerable" ratings.

Overall, insurers perform much better in the peak years than in the trough years and there is less volatility in the peak years. For comparison, we pick up several ratings to represent their groups and contrast their performances in different economic periods in Table 6. Table 6 lists the performance of four initial rating points: $\mathrm{A}-, \mathrm{B}++$, $\mathrm{C}++$ and $\mathrm{D}$ in the three economic cycles. We calculate their upgrade, no change, downgrade and NR intensities from Table 5. For example, insurers starting with "A-" have 8.96 per cent probability to be upgraded, 83.48 per cent probability to have no change, 5.75 per cent probability to be downgraded and 1.81 per cent probability to go to "NR" in the economic peak years. Overall, insurers have more upgrades and less volatility in the economic peak years. And also there is less likelihood to go to "NR" in the peak years. Most striking of all, insurers starting with D have no chance to go to liquidation status ("F") in the peak years, contrasting with a 20 per cent of probability in the trough years. So we can conclude that variations in insurer rating transitions are attributable to economic cycles.

\section{Conditional matrices on industrial cycles}

A cyclical pattern of underwriting results is frequently observed in the property and liability insurance industry. In a "hard" market, underwriting standards are tight and premiums go high; in a "soft" market, underwriting standards become loose and premiums are low. Table 7 reports the rating transition probabilities on the stage of the underwriting cycles. Here we use NPW growth to ascertain the status of the underwriting cycle. In our sample period, the NPW growth is dramatically high in 2001, 2002, and 2003. We call those three years a "hard" market, and the other years a 


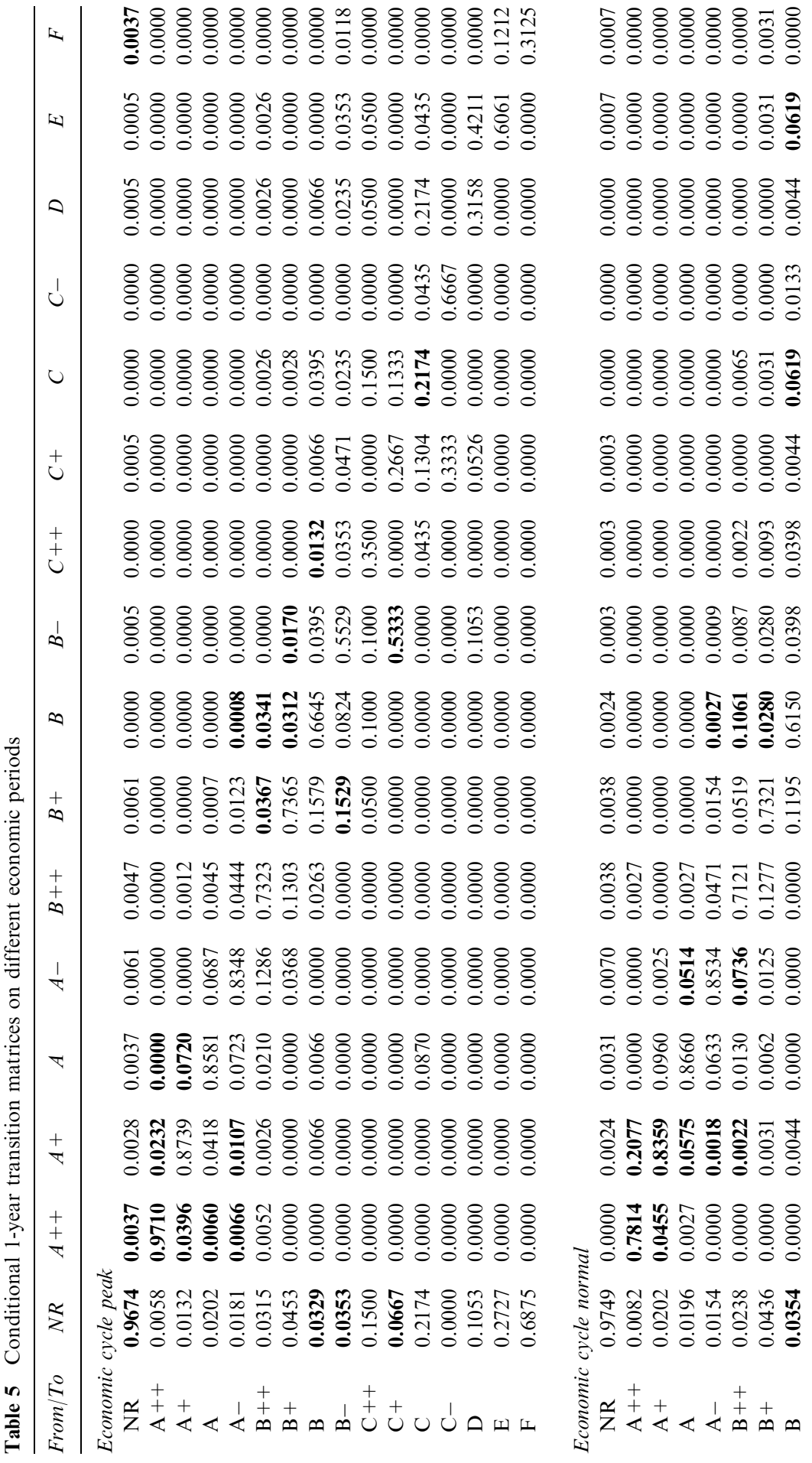




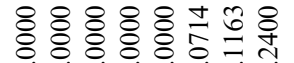
0.000000

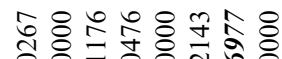

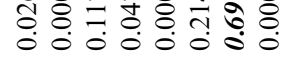

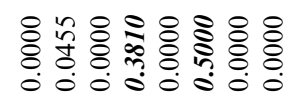

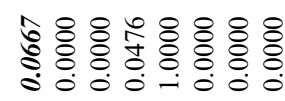

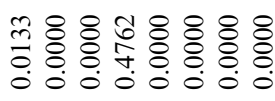

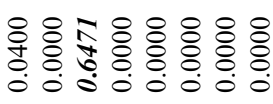

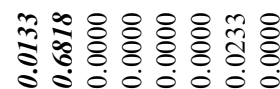

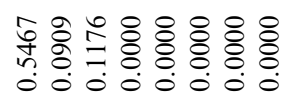

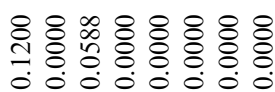

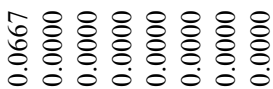

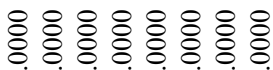
○ 0 ○

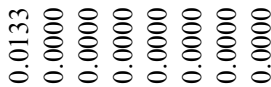

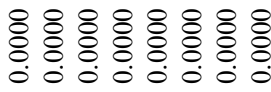

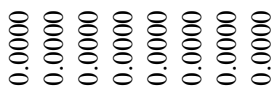

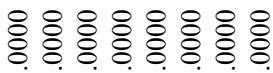
0.090 .00

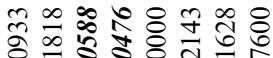
0.000000

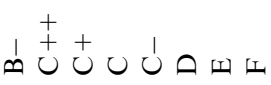

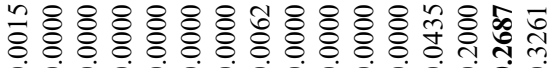
0000000000

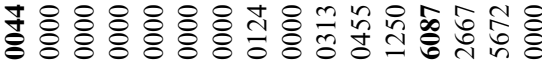
迥

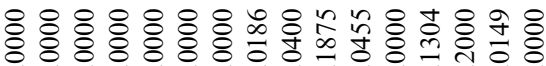
0000000000000

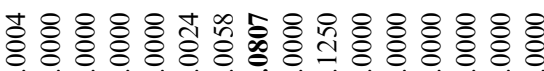
0000000000000000

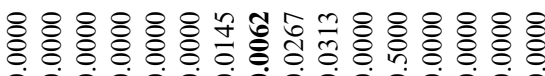

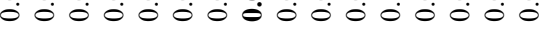

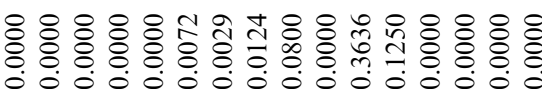

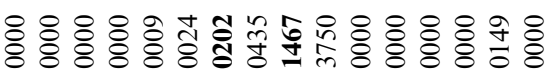
00000000000

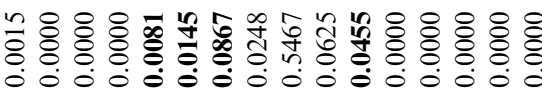

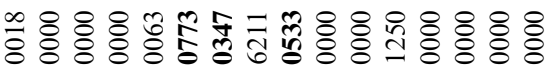
0000000000000

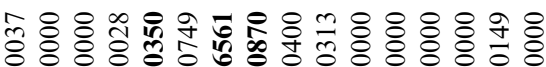

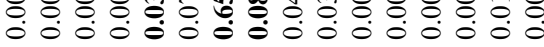

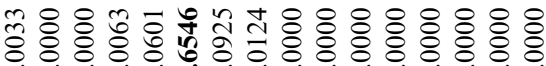

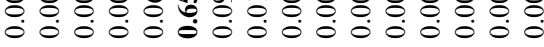

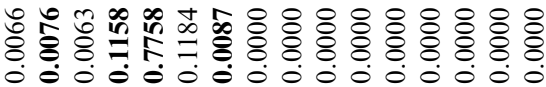

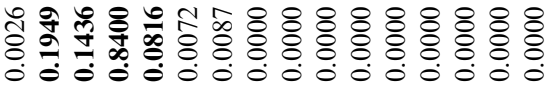

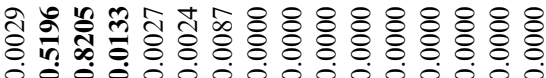

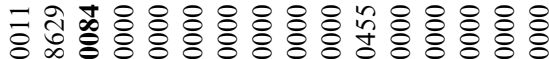
50.00000000000000

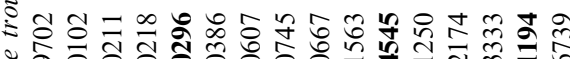

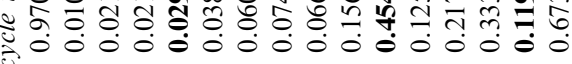

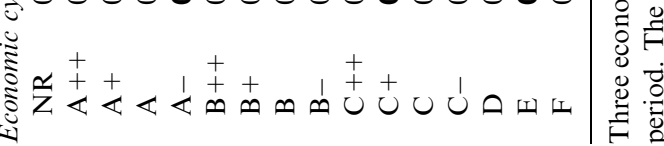


Table 6 Comparisons for selected ratings in the different economic periods $(\%)$

\begin{tabular}{|c|c|c|c|c|}
\hline From & Upgrade & No Change & Downgrade & To NR \\
\hline \multicolumn{5}{|l|}{$A-$} \\
\hline Peak & 8.96 & 83.48 & 5.75 & 1.81 \\
\hline Normal & 6.51 & 85.34 & 6.61 & 1.54 \\
\hline Trough & 8.43 & 77.58 & 11.04 & 2.96 \\
\hline \multicolumn{5}{|l|}{$B++$} \\
\hline Peak & 15.70 & 73.23 & 7.86 & 3.15 \\
\hline Normal & 8.88 & 71.21 & 17.54 & 2.38 \\
\hline Trough & 12.80 & 65.46 & 17.88 & 3.86 \\
\hline \multicolumn{5}{|l|}{$C++$} \\
\hline Peak & 25 & 35 & 25 & 15 \\
\hline Normal & 9.09 & 68.18 & 4.55 & 18.18 \\
\hline Trough & 9.38 & 37.50 & 37.50 & 15.62 \\
\hline \multicolumn{5}{|l|}{$D$} \\
\hline Peak & 15.79 & 31.58 & $42.11^{\mathrm{a}}$ & 10.53 \\
\hline Normal & 0.00 & 50 & $28.57^{\mathrm{b}}$ & 21.43 \\
\hline Trough & 0.00 & 20 & $46.67^{\mathrm{c}}$ & 33.33 \\
\hline
\end{tabular}

aNo observation exits to "F", a liquidation status.

bAmong 28.57 per cent down-grades, 7.14 per cent of D go to "F".

"Among 46.67 per cent down-grades, 20 per cent of D go to "F".

Four initial ratings: $\mathrm{A}-, \mathrm{B}++, \mathrm{C}++$, and $\mathrm{D}$ are picked up to compare the different probabilities of transitions among three economic cycles: Peak, Normal, and Trough.

"soft" market. Similar to above, the statistically significant $(p \leqslant 0.05)$ probabilities appear in bold type. Surprisingly, the significant different probabilities for both the hard market and soft market from the unconditional probabilities are similarly distributed. This may be caused by the opposite effects of the hard market and the soft market on the rating transitions.

We also compare the performances of different initial rating groups under different underwriting cycles in Table 8. Overall, insurer ratings are more stable in the soft markets as they appear more likely to stay at their starting points. There are more down-grades than up-grades in the hard market, while there are more up-grades than down-grades in most cases except D in the soft market. Also, insurers starting with "D" are more likely to go liquidated in the hard market: 22.73 per cent in the hard market vs. 6.25 per cent in the soft market. All of these confirm that industry cycles contribute to rating transition probabilities.

\section{Model estimate}

To further analyse the effects of economic and industrial cycles on insurer rating transitions, we calculate the annual upgrade rate, downgrade rate and NR rate and use least squares regressions to model the effects. The annual upgrade rate is calculated as the number of upgrade transitions over the total number of rating assignments within a year, the annual downgrade rate is calculated as the number of downgrade 


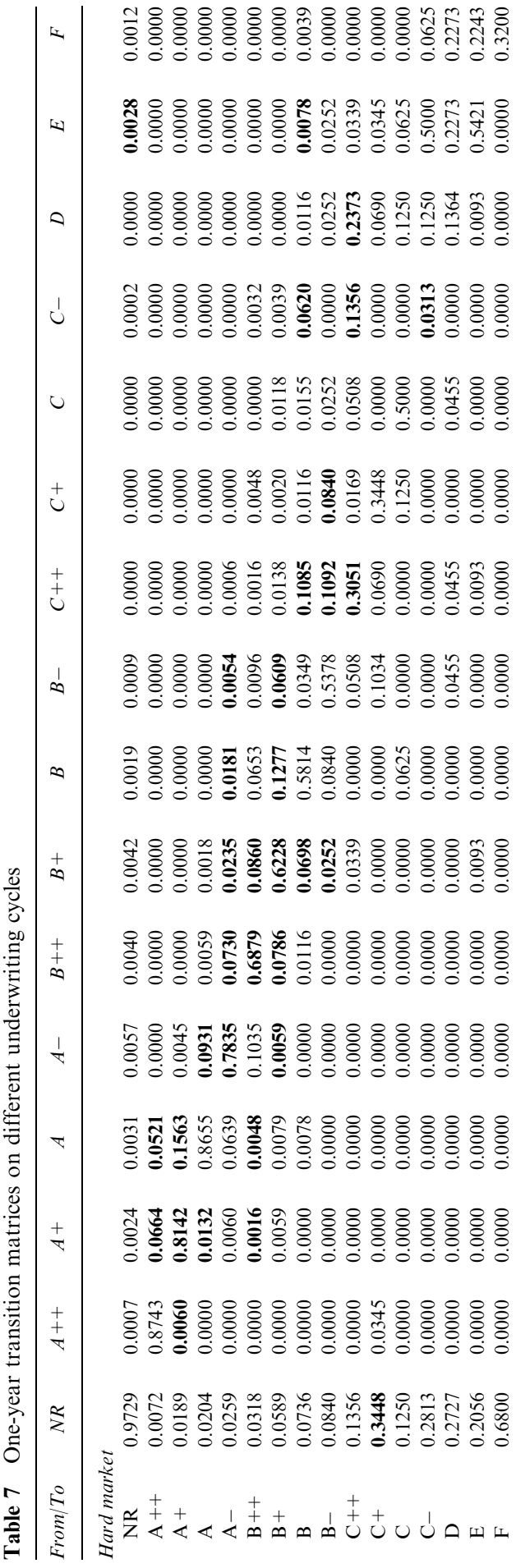

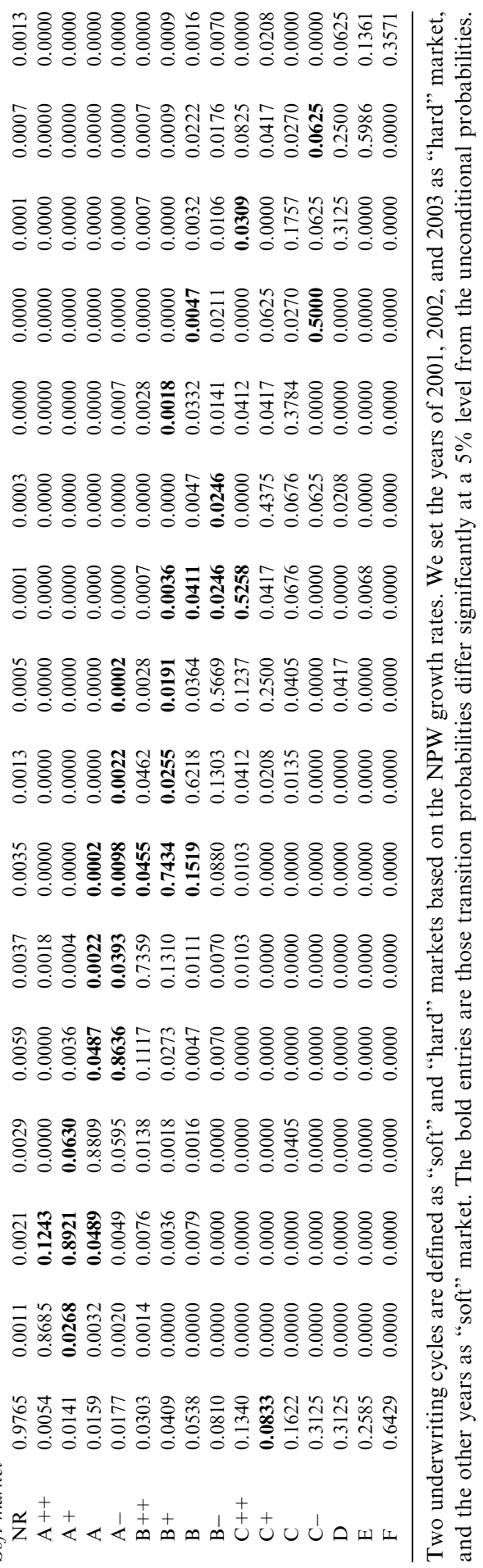


Table 8 Comparisons for selected ratings in the different industry cycles (\%)

\begin{tabular}{|c|c|c|c|c|}
\hline From & Upgrade & No Change & Downgrade & To NR \\
\hline \multicolumn{5}{|l|}{$A-$} \\
\hline Hard & 6.99 & 78.35 & 12.07 & 2.59 \\
\hline Soft & 6.64 & 86.36 & 5.32 & 1.77 \\
\hline \multicolumn{5}{|l|}{$B++$} \\
\hline Hard & 10.99 & 68.79 & 17.05 & 3.18 \\
\hline Soft & 13.45 & 73.59 & 9.93 & 3.03 \\
\hline \multicolumn{5}{|l|}{$C++$} \\
\hline Hard & 8.47 & 30.51 & 47.46 & 13.56 \\
\hline Soft & 18.56 & 52.58 & 15.46 & 13.40 \\
\hline \multicolumn{5}{|l|}{$D$} \\
\hline Hard & 13.64 & 13.64 & $45.45^{\mathrm{a}}$ & 27.27 \\
\hline Soft & 6.25 & 31.25 & $37.50^{\mathrm{b}}$ & 31.25 \\
\hline
\end{tabular}

"Among 45.45 per cent down-grades, 22.73 per cent of D exit to "F", a liquidation status.

'Among 37.50 per cent down-grades, 6.25 per cent of $\mathrm{D}$ go to " $\mathrm{F}$ ".

Four initial ratings: $\mathrm{A}-, \mathrm{B}++, \mathrm{C}++$ and $\mathrm{D}$ are picked up to compare the different probabilities of transitions between two industry cycles: "hard" and "soft" market.

transitions over the total number of rating assignments in a year, and the annual NR rate is calculated as the number of NR transitions over the total number of rating assignments in a year. This measurement captures the effects of multiple rating migrations for an insurance company within a year.

As the correlation between GDP growth and NPW growth is significantly high $(-0.71)$, univariate analyses are used here.

$$
\begin{aligned}
& \text { Upgrade Rate }_{t}=\alpha_{1}+\beta_{1} \tau X_{G D P t}+\varepsilon_{1 t} \\
& \text { Upgrade Rate }_{t}=\alpha_{2}+\beta_{2} \tau X_{N P W t}+\varepsilon_{2 t} \\
& \text { Downgrade Rate } t=\Pi_{1}+\gamma_{1} \tau X_{G D P t}+\lambda_{1 t} \\
& \text { Downgrade Rate }_{t}=\Pi_{2}+\gamma_{2} \tau X_{N P W t}+\lambda_{2 t} \\
& \text { NR Rate }_{t}=\delta_{1}+\theta_{1} \tau X_{G D P} t+v_{1 t} \\
& \text { NR Rate }_{t}=\delta_{2}+\theta_{2} \tau X_{G D P t}+v_{2 t}
\end{aligned}
$$

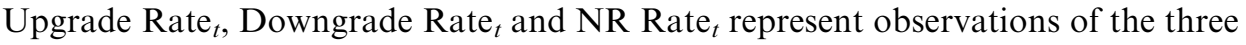
dependent variables for the year $t . X_{G D P t}$ is the independent variable GDP growth in year $t ; X_{N P W t}$ is the independent variable NPW growth in year $t ; \alpha_{1}, \alpha_{2}, \Pi_{1}, \Pi_{2}, \delta_{1}$, and $\delta_{2}$ are intercept estimates; $\varepsilon_{1 t}, \varepsilon_{2 t}, \lambda_{1 t}, \lambda_{2 t}, v_{1 t}$, and $v_{2 t}$ are random errors.

Table 9 shows the parameter estimates for the above six equations. GDP growth plays an important role in overall upgrade and downgrade transitions. It is positively 
Table 9 Regression Results

\begin{tabular}{|c|c|c|c|c|c|c|c|c|c|}
\hline & \multicolumn{3}{|c|}{ Upgrade rate } & \multicolumn{3}{|c|}{ Downgrade rate } & \multicolumn{3}{|c|}{$N R$ rate } \\
\hline & Coefficient & $\begin{array}{c}\text { Standard } \\
\text { error }\end{array}$ & $P$-value & Coefficient & $\begin{array}{c}\text { Standard } \\
\text { error }\end{array}$ & $P$-value & Coefficient & $\begin{array}{c}\text { Standard } \\
\text { error }\end{array}$ & $P$-value \\
\hline Intercept & 0.0131 & 0.0184 & 0.4971 & 0.1117 & 0.0261 & 0.0027 & 0.0306 & 0.0048 & 0.0002 \\
\hline GDP growth & 1.2248 & 0.5494 & 0.0563 & -1.4668 & 0.7799 & 0.0968 & -0.1901 & 0.1435 & 0.2219 \\
\hline$R^{2}$ & 0.3832 & & & 0.3066 & & & 0.1799 & & \\
\hline Intercept & 0.0673 & 0.0110 & 0.0003 & 0.0362 & 0.0115 & 0.0135 & 0.0226 & 0.0028 & 0.0000 \\
\hline NPW growth & -0.3156 & 0.1733 & 0.1060 & 0.5903 & 0.1806 & 0.0114 & 0.0405 & 0.0444 & 0.3887 \\
\hline$R^{2}$ & 0.2931 & & & 0.5719 & & & 0.0941 & & \\
\hline
\end{tabular}

Univariate results for "GDP growth" and "NPW growth" are reported with three dependent variables: upgrade rate, downgrade rate, and NR rate.

related to upgrade rate and negatively related to downgrade rate both at less than 10 per cent confidence levels. NPW growth is negatively related to upgrade rate at a little bit higher than 10 per cent confidence level, and significantly positively related to downgrade rate at about 1 per cent confidence level. Of particular note, approximately 57 per cent of the variations in the downgrade rate can be explained by NPW growth. For the NR rate, both GDP growth and NPW growth show the same direction as they do in the downgrade rate, though neither estimate is significantly different from zero. This suggests that the other factors, for example, firm-specific conditions, may lead to the NR transitions.

\section{Summary}

The role of insurer credit ratings has not been studied as extensively as that of bond ratings. Insurance credit risks are subject to insurance-related finance transactions and regulations, which are different from bond credit risks, so that the general bond rating transitions may not be appropriate for assessing insurance credit risks. In addition, credit rating agencies play an important role in monitoring the insurers' solvency. The tremendous information offered by the rating agencies reflects all kinds of financial risks an insurer is facing, which practitioners and academics alike should make use of in the measurement and management of those risks. We expect that the results here will have implications for various parties. Regulators may pay more attention to the changes in capital structure after the rating changes and analyse whether it is caused by the general economic and market conditions or the insurer itself. Consumers want to buy safe insurance products, so they may make different purchase decisions across different economic and market periods. Investors, usually holding stocks or bonds issued by publicly traded insurance companies, get to know the influence of the exogenous environments to the rating changes and then price changes.

This research has utilised insurer rating data and studied transition patterns under different economic and industrial periods. Insurer ratings represent an insurer's credit status: whether it can meet its obligation when the promised contingency occurs. For the first time, the unconditional and conditional matrices for U.S. property-liability 
450

insurer ratings during the period 1995-2006 are calculated and compared across different economic and industry cycles. We find that insurer rating transition probabilities are influenced by different economic and industrial cycles. When the exogenous environment is favourable, insurer ratings are more stable and changes tend to be up-grades, and vice versa. The results of regression analyses generally confirm the importance of economic and industrial factors on insurer rating migrations. We also find that the likelihood of moving to the not-rated category (NR) for an insurer generally increases as the economic and industrial conditions deteriorate through the analysis of transition matrices. However, the results of the regression analyses indicate that other factors, for example, the other macroeconomic conditions or rating movement itself, may play important roles in such transitions, which indicates that further research would improve the understanding of changes in insurer ratings. ${ }^{23}$

\section{References}

A.M. Best Company (2008a) 2008 Best's Insurance Reports-Property/Casualty, Oldwick, NJ: A.M. Best. A.M. Best Company (2008b) Best's Impairment Rate and Rating Transition Study - 1977 to 2007, Oldwick, NJ: A.M. Best.

Bangia, A., Diebold, F.X., Kronimus, A., Schagen, C. and Schuermann, T. (2002) 'Ratings migration and the business cycle, with application to credit portfolio stress testing', Journal of Banking and Finance 26(2-3): 445-474.

Browne, M.J., Carson, J.M. and Hoyt, R.E. (1999) 'Economic and market predictors of insolvencies in the life-health insurance industry', Journal of Risk and Insurance 66(4): 643-659.

Browne, M.J. and Hoyt, R.E. (1995) 'Economic and market predictors of insolvencies in the propertyliability insurance industry', Journal of Risk and Insurance 62(2): 309-327.

Carty, L.V. (1997) Moody's Rating Migration and Credit Quality Correlation, 1920-1996. Special Comment, New York: Moody's Investors Service.

Carty, L.V. and Lieberman, D. (1996) Corporate Bond Defaults and Default Rates 1938-1995, New York: Moody's Investors Service.

Cummins, J.D. and Nini, G.P. (2002) 'Optimal capital utilization by financial firms: Evidence from the property-liability insurance industry', Journal of Financial Services Research 21(1-2): 15-53.

Duffie, D., Saita, L. and Wang, K. (2007) 'Multi-period corporate default prediction with stochastic covariates', Journal of Financial Economics 83(3): 635-665.

Epermanis, K. and Harrington, S.E. (2006) 'Market discipline in property/casualty insurance: evidence from premium growth surrounding changes in financial strength ratings', Journal of Money, Credit and Banking 38: $1515-1544$.

Figlewski, S., Fryman, H. and Liang, W. (2008) Modeling the effect of macroeconomic factors on corporate default and credit rating transitions, Working Paper, New York University.

Gaver, J.J. and Pottier, S.W. (2005) 'The role of holding company financial information in the insurer-rating process: Evidence from the property-liability industry', Journal of Risk and Insurance 72: 77-103.

Kavvathas, D. (2001) Estimating credit rating transition probabilities for corporate bonds, Working Paper, University of Chicago.

Lando, D. and Skødeberg, T. (2002) 'Analyzing ratings transitions and rating drift with continuous observations', Journal of Banking and Finance 26(2-3): 423-444.

Nickell, P., Perraudin, W. and Varotto, S. (2000) 'Stability of ratings transitions', Journal of Banking and Finance 24(1-2): 203-227.

${ }^{23}$ Wang and Carson (2009a) examined the influence of a comprehensive set of macroeconomic and industrial factors to insurer rating movements. Wang and Carson (2009b) found strong evidence of nonMarkovian behaviours present in insurer rating movements. 
Phillips, R.D., Cummins, J.D. and Allen, F. (1998) 'Financial pricing in the multiple line insurance company', Journal of Risk and Insurance 65: 597-636.

Pottier, S.W. and Sommer, D.W. (1999) 'Property-liability insurer financial strength ratings: Differences across rating agencies', Journal of Risk and Insurance 66: 621-642.

Sommer, D.W. (1996) 'The impact of firm risk on property-liability insurance prices', Journal of Risk and Insurance 63(3): 501-514.

Wang, Y.L. and Carson, J. (2009a) Macroeconomic factors and property-liability insurer rating transitions, Working Paper, Florida State University.

Wang, Y.L. and Carson, J. (2009b) Non-Markov effects and property-liability insurer rating transitions, Working Paper, Florida State University.

\begin{abstract}
About the Author
Yuling Wang earned a Master of Arts degree in Finance at University of NebraskaLincoln in 2003. She then earned a Ph.D. degree in Risk Management/Insurance at Florida State University in 2009. She is now an Assistant Professor in the Shanghai University of Finance and Economics.
\end{abstract}

